\title{
O DIREITO E OS POVOS INDÍGENAS DO BRASIL: UMA NOVA PERSPECTIVA DE DIREITOS HUMANOS
}

\author{
THE LAW AND THE INDIGENOUS PEOPLES IN BRAZIL: A NEW \\ HUMAN RIGHTS PERSPECTIVE
}

\begin{abstract}
Cecília de Castro Algayer ${ }^{1}$
Afonso Maria das Chagasa ${ }^{\text {II }}$ (i)

${ }^{\text {I } U n i v e r s i d a d e ~ F e d e r a l ~ d e ~ M a t o ~ G r o s s o, ~}$ Cuiabá, MT, Brasil. Mestranda em

Direito. E-mail: cecilia.calgayer@gmail. com

${ }^{\text {II } U n i v e r s i d a d e ~ F e d e r a l ~ d e ~ R o n d o ̂ n i a, ~}$ Porto Velho, RO, Brasil. Doutor em

Ciência Política.E-mail: afonso.chagas@ unir.br

Resumo: A relação do Estado brasileiro com os povos indígenas tem sido historicamente marcada por um desmazelo cuidadosamente acobertado pela lei, capaz de permitir a tomada de suas terras, a violência sistêmica, a exploração e o desmonte dos instrumentos e das instituiçóes em tese criados mesmo para a defesa dessas comunidades. Diante desse cenário, a presente pesquisa adotou como marco teórico a política indigenista da Constituiçâo de 1988 para desconstruir a epistemologia eurocêntrica da fundamentação dos direitos humanos e buscar caminhos possíveis. Afinal, mesmo no plano internacional, a adoçáo de uma série de direitos tidos como universais não permitiu a emancipação dos povos indígenas à condição plena de sujeitos de direito dentro do Estado nacional, mantendo-os sob uma série de ficçôes tutelares que sempre encobertou um etnocentrismo latente. Dessa forma, pelo método dialético e com o emprego das técnicas bibliográfica e documental, foram contrastadas a realidade sócio-histórica dos povos indígenas do Brasil e o discurso dos direitos humanos para análise do caráter revolucionário do novo paradigma constitucional. Em conclusão, evidenciou-se a potencialidade emancipatória dos direitos humanos, compreendidos como espaços de luta em que se buscam concretizar as reivindicaçóes sociais especialmente as provindas daqueles povos que, por séculos, sequer foram reconhecidos como pessoas. Dessa forma, por uma ótica decolonial, concluiu-se pela abertura de uma nova arena política pela Constituição Federal de 1988, orientada à construçáo de uma sociedade pluriétnica e capaz de ressignificar a busca por direitos humanos.
\end{abstract}

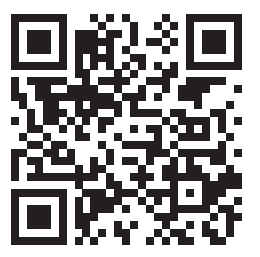

DOI: http://dx.doi.org/10.31512/rdj.v21i39.314

Recebido em: 18.07.2020

Aceito em: 17.12.2020
Palavras-chave: Direito indígena. Direito constitucional. Povos indígenas.

Abstract: The history of the Brazilian State in its relationship with indigenous peoples is marked by an indifference carefully covered by the law, capable of allowing the seizure of their lands, systemic violence, the exploitation and dismantling of instruments and institutions in theory 
created even for the defense of these communities. In view of this scenario, the present research adopted as a theoretical framework the indigenous policy of the 1988 Constitution to deconstruct the Eurocentric epistemology of the foundation of human rights and search for possible ways. After all, even at the international level, the adoption of a series of rights considered to be universal did not allow the emancipation of indigenous peoples to the full condition of subjects of law within the national State, keeping them under a series of tutelary fictions that always cov-ered up a latent ethnocentrism. In this way, through the dialectical method and the use of bibliographic and documentary techniques, the socio-historical reality of the indigenous peoples of Brazil and the human rights discourse were contrasted to analyze the revolutionary character of the new constitutional paradigm. In con-clusion, the emancipatory potential of human rights became evident, understood as spaces of struggle in which social demands are sought to be realized - especially those coming from those peoples that, for centu-ries, were not even recognized as persons. Thus, from a decolonial perspective, it was concluded that a new political arena was opened by the Federal Constitution of 1988, oriented to the construction of a multi-ethnic society and capable of reframing the search for human rights.

Keywords: Indigenous law. Constitucional law. Indigenous people.

\section{Consideraçóes iniciais}

Historicamente, o direito brasileiro nunca considerou os povos indígenas precisamente como sujeitos. Pelo contrário, em mais de cinco séculos, a ordem jurídica calcada nos fundamentos europeus que se construiu no Brasil sempre se orientou à perpetuaçáo de uma sociedade predominantemente individualista, patrimonialista e branca, relegando aos povos tradicionais o impreciso e colonialista rótulo de índios, ignorando tratarem-se de etnias diversas e empurrando para as margens da legislação as disposiçôes que lhes eram concernentes.

Quando os europeus aportaram no Brasil, o território já era multicultural. Estima-se a existência de cerca de quatrocentos povos diferentes, cujos conflitos e rivalidades internas perfaziam um cenário muito menos violento do que o que estava prestes a ser imposto pelo avanço colonizatório (PERUZZO, 2017, p. 9).

A despeito dessa diversidade, o olhar dirigido aos povos indígenas os enquadrou desde o princípio como objetos de curiosidade e estudo, e não propriamente como pessoas (CASTRO, 2020, p. 161), resultando assim no conceito colonial de índio, uma classificação homogeneizante e abstrata inapta a traduzir a pluralidade dos povos originários.

E, se classificar algo a partir de nossos próprios referenciais cognitivos já configura um problema epistemológico antigo, ressuscitando todas as questôes concernentes à relação sujeito- 
objeto, classificar um outro alguém sem se permitir o conhecimento mais completo possível com esse sujeito constitui um problema ainda mais grave; pois "[...] se as coisas não perdem nada ao serem classificadas de forma unilateral, os seres humanos perdem muito, pois perdem a dignidade que constitui sua essência” (PERUZZO, 2016, p. 14).

É fato notório que os europeus não estavam minimamente preocupados com a dignidade ou a essência dos povos indígenas. Após um dos maiores cataclismos biológicos do mundo, inúmeras populaçóes pré-colombianas desapareceram da face da terra em um morticínio fruto de um processo complexo, movido tanto pela ação humana quanto por letais epidemias, pela ganância e pela ambição do capitalismo mercantil (CUNHA, 2012, p. 14).

Ao averiguar o decréscimo populacional ocorrido nas Américas a partir dos processos colonizatórios, Dobyns (1966, p. 414) estima um perecimento na proporção de 20 para 1, especulando uma reduçáo populacional de 90 milhóes de habitantes tradicionais do continente americano para apenas 4,5 milhóes.

No Brasil, a sobrevivência dos povos indígenas aos dias atuais chegou a desafiar o otimismo de diversos antropólogos, dentre eles Darcy Ribeiro (2017, p. 16), que, no prefácio da $7^{\text {a }}$ edição de Os indios e a civilização, teve de reconhecer um aumento esperançoso no contingente populacional dos povos indígenas, em contraste com suas expectativas ao terminar a primeira versão da obra, em 1970.

Após séculos de genocídio, atualmente a população indígena do Brasil perfaz um contingente significativo de aproximadamente 896.917 pessoas, distribuídas em 256 povos e falantes de 274 línguas diferentes, além do português (INSTITUTO SOCIOAMBIENTAL ISA, 2020, n.p.).

Quando toda a legislação brasileira anterior à Constituição Federal de 1988 tratava dos povos indígenas como certamente destinados à natural extinção, essa permanência (agora constitucionalmente garantida e protegida) desafia o Estado e seu aparato ainda marcados pela colonialidade.

Face à permanência indígena e à continuidade de sua luta histórico-política por reconhecimento, a presente pesquisa buscou compreender a relação entre os povos indígenas e o Estado brasileiro, durante o período de sua formação, para contrastá-la ao discurso hegemônico dos direitos humanos e analisar o descompasso entre ambos.

A partir de então, a própria natureza dos direitos humanos foi investigada por meio da análise da revolução paradigmática promovida pela Constituição Federal de 1988, que buscou emancipar os povos indígenas e traduzir, com isso, o caráter socialmente revolucionário da busca (e da conquista) por direitos fundamentais.

Dessa forma, por meio do método dialético e com uso das técnicas de pesquisa bibliográfica e documental, averiguou-se o reconhecimento por parte da Constituição da colonialidade que até então marcava a política indigenista nacional: mais além, buscou-se encontrar indícios de sua ruptura, no prenúncio de uma ordem jurídica mais democrática e também mais pluralista. 


\section{A narrativa dos Direitos Humanos sob uma perspectiva decolonial}

A partir da Magna Carta inglesa do século XIII, o desenvolvimento dos direitos humanos percorreu três revoluçóes - a Gloriosa, no século XVII, e a Americana e a Francesa, no século seguinte - até culminar com a Declaração Universal de Direitos Humanos promulgada pela Organização das Nações Unidas (ONU) em 1945.

Essa linear construção cronológica posiciona, portanto, o Ocidente como o espaço em que progressivamente desenvolveu-se a emancipação do homem moderno e o reconhecimento de seu valor, traduzidos em conceitos posteriormente estendíveis a toda a humanidade.

Para além da enunciação de direitos que se propunham universais, Hannah Arendt (2011, p. 234) denuncia, contudo, a íntima ligação entre propriedade e liberdade no cerne do desenvolvimento dos direitos humanos, sendo a primeira garantia da segunda.

É em razão disso que se pode afirmar que as declaraçôes modernas, ao menos a princípio, não visavam à promoção de uma vida digna para todos os seres humanos, mas, sim, à garantia do exercício da liberdade para quem fosse capaz de exercê-la por suas próprias forças (BRAGATO, 2014, p. 210).

Nos termos de Alvarenga (2015, p. 163), isso é dizer que a concepção liberal dos direitos humanos sempre afirmou "[...] direitos individuais de uma determinada cultura central em detrimento dos direitos coletivos das culturas periféricas".

Em suas versóes pós-guerra, os instrumentos promotores de direitos humanos se fundaram principalmente no direito à igualdade, fruto de uma ideologia liberal capaz de responder a fenômenos como o apartheid, mas também capaz de transmutar-se em homogeneidade cultural e redundar em um dever de assimilação generoso apenas com o indivíduo, nunca com o grupo; capaz de aceitar todas as pessoas, sim, mas desde que se despojassem de suas particularidades étnicas, em um etnocentrismo cego a si mesmo (CUNHA, 2012, p. 129).

Em decorrência dessa prevalência hegemônica, imposta pela força dos processos colonizatórios, as sociedades, o conhecimento e o próprio direito foram sendo produzidos ao redor do mundo ocidental "[...] a partir das categorias epistemológicas, antropológicas, políticas e históricas do pensamento europeu” (BRAGATO, 2014, p. 213), com o descarte das outras formas de conhecimento (e de seus titulares) produzidas fora desses padróes dominantes.

Para Boaventura de Sousa Santos (2007, p. 71), essa diferenciação se materializa mesmo na atualidade no traçado de uma linha abissal entre dois mundos: o primeiro desenvolvido, racional e progressista; o segundo, primitivo, selvagem e desordenado.

De um lado, se encontra o conhecimento científico; do outro, os conhecimentos populares, leigos, plebeus, camponeses ou indígenas, "[...] que desaparecem como conhecimentos relevantes ou comensuráveis por se encontrarem para além do universo do verdadeiro e do falso" (SANTOS, 2007, p. 73). 
Para Castro (2020, p. 165), a sustentação desse processo excludente se deu historicamente pela desqualificação da produção desses conhecimentos e também de seus sujeitos, por meio da racialização dos corpos dos sujeitos não europeus. Dessa forma, especialmente a partir da divisão cartesiana entre corpo e razão, certos corpos - como os indígenas e os negros - foram considerados mais próximos da natureza, ou seja, mais distantes da concepção de humanidade, e, assim, convertidos tanto em objetos de conhecimento quanto em corpos domináveis e exploráveis (QUIJANO, 2005, p. 118).

Conforme Latour (2013, p. 98) essa foi a chave da conquista colonizatória: primeiro, a separação da humanidade e da natureza, a primeira sujeito, a segunda, objeto a ser desvendado e instrumentalizado por ela. E, em consequência, a contraposição desse modelo às sociedadesnatureza, cujas concepçóes de mundo consubstanciavam um entrelaçar (ainda) indiscernível entre cultura e entorno. A partir dessa perspectiva, "[...] o outro, o diferente, estava ainda em 'estado de natureza', e por isso justificava-se sua exploração e domínio" (CASTRO, 2020, p. 166).

Em nome da missão civilizatória, foi dessa forma que as iniciativas colonizatórias europeias atribuíram a si a função de "[...] retirar o resto da humanidade de seu primitivismo, de sua irracionalidade e de seu subdesenvolvimento, para, afinal, conduzi-la rumo ao progresso e à racionalidade" (DUSSEL, 2000, p. 73).

Assim, foi com base em suas refinadas concepções de humanidade que os teóricos europeus chegaram à conclusão de que os "selvagens" não eram inteiramente humanos. E, mesmo quando o Papa Paulo III afirmou que os indígenas tinham alma, em sua bula Sublimis Deus, de 1537, a concebeu como um receptáculo vazio - uma alma anima nullius, semelhante ao conceito de terra nullius (SANTOS, 2007, p. 75), um conceito de vazio jurídico que, da mesma forma com que permitiu a exploração das terras indígenas, passaria a permitir também a exploração dos próprios indígenas.

$\mathrm{Na}$ segunda metade do século XIX, prosperou em particular a ideia de que certas sociedades "primitivas" não houvessem progredido em absoluto desde o começo da história humana, sendo, portanto, fósseis vivos que se limitavam a testemunhar o avanço das sociedades ocidentais; espectadores pueris e inertes. Dizia-se que de tais povos não havia sequer história: havia etnografia (CUNHA, 2012, p. 11).

Para o antropocentrismo moderno, afinal, a racionalidade era o caráter distintivo do ser humano. E, para a tradição europeia, o ser racional não era apenas o ser pensante - caracterizavase, pelo contrário, pelo raciocínio orientado ao domínio e à instrumentalização do mundo.

Apenas uma concepção segregacionista de racionalidade e humanidade como essa é capaz de explicar, afinal, como foi possível a própria constituição do universo colonial, com seu imenso contingente de pessoas escravizadas, discriminadas, exterminadas e oprimidas justamente por quem articulava o discurso humanista em suas próprias terras e para seus próprios pares (BRAGATO, 2014, p. 222). 
Assim, da mesma maneira que a democracia grega era dirigida a todos, sim, desde que fossem cidadãos, os direitos humanos foram desenvolvidos também para todos, nascidos livres e iguais, desde que fossem humanos, na concepção europeia do termo.

E, dentro desse contexto de desenvolvimento eurocêntrico do conhecimento, do mundo, dos Estados e do próprio direito, com o correr dos séculos os povos indígenas foram sendo sistematicamente excluídos de todos os processos de construção nacional, com a negação de sua própria humanidade e de seu consequente potencial como atores políticos.

Mesmo com a promulgação da Declaração dos Direitos Humanos, em 1945, que, além de reafirmar o conjunto dos direitos das revoluçôes burguesas, os estendeu a uma série de sujeitos que anteriormente estavam deles excluídos - com a abolição da escravidão, a garantia dos direitos das mulheres, a defesa dos direitos dos estrangeiros - a visão eurocêntrica, ainda presente, apenas se coadunou com uma noção de progresso por ela mesma construída, mantendo como base as origens das revoluçóes modernas e a expandindo magnanimamente para os demais povos do mundo (ACÇOLINI, 2010, p. 96).

É nesse cenário que Santos (2003, p. 9) questiona o potencial emancipatório do Direito, ao mesmo tempo em que desnuda a natureza ocidental dessa pergunta: pois dependente dos pressupostos de identificação do Direito como campo social distinto, autônomo e homogêneo; de um conceito genérico de emancipação social; e da existência de expectativas sociais alcançáveis, tudo em um cenário superveniente a quinhentos anos de expansão europeia em alto nível de globalização hegemônica.

A contra-hegemonia talvez sugira uma resposta. Nesse cenário, o giro decolonial representa a compreensão de que o fim do processo histórico do colonialismo não significou uma transformação significativa no tocante à divisão do trabalho, à separaçáo entre centros e periferias, bem como quanto à hierarquização étnico-racial (CURIEL, 2020, p. 143).

Conforme Quijano (2005, p. 108), a atual colonialidade do poder significa a manutenção de relações de exploração em torno da disputa pelo controle e pelo domínio do trabalho; dos recursos naturais; do sexo; da subjetividade; e, dentre ela, também do conhecimento e da autoridade. Trata-se, dessa forma, da transição do colonialismo moderno à colonialidade global.

Para Miñoso (2020, p. 112), a perspectiva decolonial, em contraponto, desafia essa posição da modernidade ocidental como projeto máximo da evolução humana, desnudando-a como um projeto imperialista e racista. Objetiva, dessa forma, o reconhecimento da permanência desses processos de colonialidade, ainda comprometidos com a manutenção dos fundamentos da superioridade europeia e de seu etnocentrismo, para que se possam enfraquecer e combater as opressões das quais resultam as grandes fissuras e mazelas sociais.

Assim, uma perspectiva decolonial envolve

[...] entender que tanto a raça quanto o gênero, a classe, a heterossexualidade etc. são constitutivos da episteme moderna colonial; elas não são simples eixos de diferenças, 
são diferenciaçóes produzidas pelas opressões, de maneira imbricada, que produzem o sistema colonial moderno (CURIEL, 2020, p. 150).

É nesse sentido que, para Herrera Flores (2009, p. 20), a redefinição teórica dos direitos humanos é indispensável para sua defesa: três décadas de neoliberalismo globalizado e a "gestáo" dos direitos humanos por organismos internacionais têm se mostrado fenômenos capazes de desestabilizar a compreensão não só da própria radicalidade do direito, mas principalmente dos direitos humanos e de seu potencial transformador.

Como se demonstrará a seguir, o desequilíbrio entre esse discurso dos direitos humanos - estabilizado, inofensivo ao status quo e já incorporado pelo mercado - e a relação do Estado brasileiro em relação aos povos indígenas, a partir de um panorama histórico, é exemplo dessa insuficiência prático-teórica, que se concretiza às expensas de grupos vulneráveis de pessoas, em contraste vivo com as disposiçóes normativas e em desafio às tentativas coloniais de universalidade.

\section{Os povos indígenas pela ótica jurídica}

No Brasil, a relação do Estado com os povos indígenas cambaleou ao longo dos séculos por períodos de franca hostilidade e também de silenciosa tolerância, na medida em que os povos pudessem ser úteis e apenas nessas circunstâncias. Por pouco tempo perdurou a visão propagandista, imortalizada na história, de indígenas e portugueses trocando espelhos, machados e riquezas. Com a transformação do Brasil em colônia, tornou-se urgente a necessidade de mão de obra para a edificação das estruturas coloniais, dando início a um longo período escravocrata.

Isso se deu mesmo com a proibiçáo, em 1548, da tomada de indígenas em cativeiro, salvo os tomados em guerra justa e salteadores - proibiçáo repetida em 1570 e reescrita, com o passar dos séculos, de diversas maneiras ao longo do ordenamento jurídico português.

Para Souza Filho (2018, p. 55), de maneira irônica, é assim “[...] reiterada a legislação colonial portuguesa proibindo a escravidão dos indígenas, mas, ao mesmo tempo, buscando fórmulas mágicas de os submeter ao trabalho produtivo segundo os parâmetros da colonização".

Em 1808, por exemplo, com a Carta Régia que declarou guerra aos índios Botocudos da então província de São Paulo, determinou-se que os prisioneiros fossem obrigados a servir por quinze anos aos seus captores, em sistema que, conforme a Carta, não se tratava de escravidão, mas de educá-los a uma convivência doce e pacífica (BRASIL, 1808, n.p.).

Essa escravidão vinha, conforme Cunha (2012, p. 82) expressa em termos pedagógicos: "[...] dobrando-os à agricultura e aos ofícios mecânicos, deveria fazer-lhes perder sua 'atrocidade' e, sujeitando-os ao trabalho como os sujeitava às leis, elevá-los a uma condição propriamente social, isto é, humana”.

Em 1757, o Marquês de Pombal, ministro de D. João I, criou o Diretório dos Índios para regulamentar o trabalho compulsório, elaborando uma série de medidas com vistas a melhor habilitar os indígenas ao trabalho. Dentre elas, a proibição do uso de línguas indígenas; 
a obrigatoriedade de frequência na escola; a proibição da nudez; a criação de sobrenomes portugueses; o incentivo à "mestiçagem"; e a transformação de aldeias em povoaçôes e vilas (SUCHANEK, 2012, p. 249).

A dita mestiçagem, conforme Peruzzo (2017, p. 7), “[...] antes de poder ser visto como um processo bonito, colorido e rico, merece ser encarado com a crueza da realidade dos abusos sexuais de crianças, adolescentes e mulheres". A violência sexual contra as mulheres indígenas é um ponto em comum entre todas as histórias das mais diversas etnias em contato com o homem branco, tendo se repetido inclusive durante a ditadura civil-militar, como demonstrado pelo Relatório Figueiredo e pelo Relatório Final da Comissão Nacional da Verdade - CNV (2014).

Em todas as suas formas, a escravidão indígena foi apenas abolida em 1831, com a revogação da Carta Régia de 1808 e a subsequente imposição de um regime tutelar dito orfanológico, que visava à proteçáo dos indígenas libertos ao mantê-los sob os cuidados dos Juízes de Órfãos. A estes juízes cabia recorrer ao Tesouro para o sustento dos indígenas ou depositá-los onde tivessem salários ou pudessem aprender ofícios úteis.

A prevalência do costume sobre a lei, no entanto, manteve a escravidão indígena por décadas após a abolição formal. Além disso, muitos foram os casos em que as autoridades se valeram do regime tutelar para arrendar e aforar terras indígenas; e, para Malheiro (1867, p. 124, apud DORNELLES, 2018, p. 90), a lei de 1831, que deveria ter posto fim ao sistema de terror imposto sobre os indígenas, apenas os sujeitou à escravidão “[...] disfarçada em servidão temporária e mesmo indefinida”.

À época, a tutela orfanológica fora concebida apenas para os indígenas libertos do cativeiro, como prisioneiros de guerra ou salteadores, com vistas a desonerá-los da escravidão e colocá-los sob a proteção estatal. De maneira curiosa, no entanto, sua aplicação foi confundida de tal forma que se misturou à proteção concedida aos bens indígenas de maneira geral; no advento da República, era comum o entendimento de que todos os indígenas estavam protegidos, assim como seus bens, pela tutela orfanológica (SOUZA FILHO, 2018, p. 96).

Dentro da premissa de instrumento nuclear do assimilacionismo como técnica de conquista (OLIVEIRA, 2016, p. 221), capaz de dirigir o processo de integração e de intermediar em caráter permanente a relaçáo do elemento diferente com o restante da sociedade, a tutela é

[...] um instrumento da missão civilizadora, uma proteçâo concedida a essas "grandes crianças" até que elas cresçam e venham a ser "como nós". Ou seja, respeita-se o índio como homem, mas exige-se que se despoje de sua condiçấo étnica específica (CUNHA, 2012, p. 114).

Historicamente, o Brasil conheceu três regimes tutelares sobre os povos indígenas: pelos missionários, pelos particulares (por meio da servidão) e pelo próprio Estado. A partir do Código Civil de 1916, a inclusão dos povos indígenas no rol dos relativamente incapazes fez remissão a uma legislação especial, afirmando, em seu art. $6^{\circ}$, parágrafo único, que os indígenas ficariam 
sujeitos ao regime tutelar que cessaria à medida em que fossem “[...] se adaptando à civilização do país" (BRASIL, 1916, n.p.).

A tutela sempre foi um instituto civilista, pertencente ao direito de família e pautada pelas disposiçôes da lei civil. Dessa forma, em retrospecto, a oferta do Estado aos indígenas da tutela orfanológica pode ser considerada uma solução jurídica frágil, pois a tutela - desde o direito romano - também sempre foi instrumento de proteção individual, incabível para uma coletividade e mais ainda para várias coletividades cultural e etnicamente diferenciadas.

Nos termos de Souza Filho (2018, p. 98), os indígenas necessitavam de uma proteção que os garantisse "[...] não só enquanto indivíduos, mas enquanto povos, na relação não só com outros cidadãos, mas com o próprio Estado”.

Apenas em 1928, com a promulgação do Decreto 5.484, legisladores e juristas conseguiram desenvolver um instituto tutelar de natureza pública, emancipando da tutela orfanológica vigente todos os indígenas nascidos no território nacional, qualquer que fosse o grau de civilização em que se encontrassem (BRASIL, 1928, n.p.).

Apesar de insistir nessa linha entre civilizados e selvagens e da manutenção da generalização (reiterada na legislação brasileira) de todos os povos indígenas sob uma só denominação e um só tratamento, o decreto promoveu um avanço significativo ao reconhecer expressamente o caráter público do direito indígena, dotando também suas terras desse contorno.

Sem revogar o Código Civil, o Decreto de 1928 não falava mais em tutela, mas sim na nulidade de atos praticados entre indígenas e não indígenas desde que os primeiros não estivessem representados por funcionários responsáveis, ou seja, sem a participação do Estado.

Em razão do estágio ainda frágil do direito público naquele período, este novo instituto manteve a denominação de tutela, e o Estado passou a exercê-la por meio do Serviço de Proteção aos Índios (SPI). O avanço nas teorias publicistas ao longo das décadas seguintes poderia ter desenvolvido e ventilado as relaçóes entre o Estado e os povos indígenas, mas, ao contrário, o direito se manteve tímido, manifestando-se principalmente por meio do Estatuto do Índio, de 1973, que nesse sentido representou mais retrocessos do que melhorias.

Para Souza Filho (2018, p. 103), o Estatuto do Índio, elaborado durante a ditadura militar, visou ao rompimento do passado de corrupção perpetrado pelo SPI e acabou por rearmar a teia de opressão criada pelo direito colonial.

Isso porque, ao regulamentar o regime tutelar previsto pelo Código Civil de 1916, por exemplo, o Estatuto revogou o Decreto de 1928 e determinou a aplicação, no que fosse cabível, das disposiçóes tutelares civilistas, mantendo junto ao Estado a incumbência pela tutela dos indígenas e reiterando o ideal de emancipaçâo indígena.

Por meio deste instituto, e conforme o disposto no art. $9^{\circ}$ do Estatuto, qualquer indígena poderia requerer em juízo competente a sua liberação do regime tutelar, investindose na plenitude da capacidade civil, desde que contasse com ao menos 21 (vinte e um) anos; 
detivesse conhecimento da língua portuguesa; estivesse habilitado para o exercício de atividade útil; e gozasse de razoável compreensão dos usos e costumes da comunhão nacional (BRASIL, 1973, n.p.).

A contrario sensu, enquanto o indígena não abandonasse suas tradiçóes, práticas, costumes e crenças tradicionais, não possuiria o discernimento necessário para o gerenciamento, por si só, da própria vida e de seus pertences (FEIJÓ, 2014, p. 210), administração essa que caberia exclusivamente ao Estado.

E, mais gravemente, consoante seu art. 11, mediante decreto do Presidente da República, poderia ser declarada a "emancipação da comunidade indígena e seus membros" (BRASIL, 1973, n.p.), desde que requerida pela maioria e comprovada a sua plena integração com a comunhão nacional. $\mathrm{O}$ dispositivo, somado à interpretação do art. 21, determinava como consequência lógica o retorno das terras indígenas ao Estado, sob a posse e o domínio pleno da Uniáo.

Conforme Cunha (2018, p. 430), à época as mulheres casadas eram tuteladas pelos maridos, e os indígenas, pela União - primeiro pelo SPI e então pela Funai. A diferença crucial, no entanto, era o exame da lisura da conduta do tutor por um curador: nenhum órgão examinava a tutela do SPI ou da Funai na administração dos interesses dos povos indígenas.

E, na prestação da tutela, como náo poderia deixar de ser, o Estado muitas vezes se dividia entre o interesse público genérico e o interesse individual do tutelado. A lei e os preceitos do direito público, afinal, apontavam na direção da obediência ao interesse público; a própria natureza da tutela, ao interesse individual do tutelado.

No fim das contas, no exercício da tutela, o funcionário que praticasse ato prejudicial aos povos indígenas seria isento de culpa caso agisse sob determinação hierárquica ou dever legal. $\mathrm{O}$ art. $43, \S 1^{\circ}$, por exemplo, determinava que a renda indígena fosse preferencialmente reaplicada em atividades rentáveis ou utilizada em programas de assistência ao indígena; na prática, o tutor estava livre para aplicar a renda como entendesse melhor, sempre encontrando amparo na alegação do interesse público genérico (BRASIL, 1973, n.p.).

A tutela representava também um empecilho para o acesso dos povos indígenas à justiça, eis que, para o Poder Judiciário, apenas a Funai enquanto tutora poderia promover diretamente uma ação. E, "[...] como a Funai era justamente o órgão de que os indígenas tinham abundantes motivos para se queixar, o resultado, na prática, era que os indígenas não conseguiam entrar na justiça” (DALLARI, 1984, apud CUNHA, 2018, p. 432).

Posteriormente, durante o regime militar, em especial com a construção da Transamazônica, das usinas de Tucuruí e Balbina, do Projeto Carajás e de diversas outras obras faraônicas em nome do desenvolvimento, os povos indígenas chegaram a ser elevados a riscos à segurança nacional, com o contínuo desrespeito de seus direitos em nome do progresso do país. Conforme declaração do Ministro Rangel Reis, de janeiro de 1976: "[...] os índios não podem impedir a passagem do progresso. [...] dentro de 10 a 20 anos, não haverá mais índios no Brasil” (BRASIL, 2014, p. 251). 
E, até pouco tempo atrás, eram inexistentes dados oficiais a respeito dos 21 anos de chumbo sofridos pelas comunidades indígenas. De Sarney a Franco (1985-995), profundo silêncio; durante o governo FHC (1995-2003), as leis e comissões destinadas à concessão de indenização às vítimas jamais contemplaram os povos indígenas. Em 2007, durante o governo Lula (2003-2011), as 502 páginas da publicação Direito à memória e à verdade, da Secretaria Especial dos Direitos Humanos, não trouxeram uma única referência às violações sentidas pelos povos indígenas (VALENTE, 2017, p. 10).

Apenas em dezembro de 2014, o relatório final da Comissão Nacional da Verdade instalada pela presidente Dilma Roussef (2011-2016) incluiu um capítulo sobre povos indígenas. Pela primeira vez foi identificado um número mínimo de vítimas da ditadura: conforme o relatório, ao menos 8.350 indígenas foram mortos durante o regime militar, em decorrência da ação direta de agentes governamentais ou da sua omissão (BRASIL, 2014, p. 205)

Acredita-se, entretanto, que o número real de vítimas seja exponencialmente maior, vez que a análise se concentrou sobre uma parcela muito restrita dos povos e que "[...] há casos em que a quantidade de mortos é alta o bastante para desencorajar estimativas" (BRASIL, 2014, p. 205).

Durante o período, prisóes específicas para indígenas se tornaram comuns. Sob o nome de reformatórios ou centros de recuperação, recebiam indígenas de todas as regiōes do Brasil sob as acusaçôes mais diversas (FERREIRA; BITTENCOURT; RÊGO, 2018, p. 129).

O Relatório Figueiredo, escrito pelo promotor que percorreu o Brasil de 1968 a 1969, investigando as violaçôes de direitos perpetradas contra os povos indígenas, foi apenas redescoberto em 2012, com sete mil páginas preservadas e vinte e nove dos trinta tomos originais. A CNV, após analisa-lo, concluiu que tribos inteiras foram completamente erradicadas; que a coalisão entre membros do SPI e latifundiários promoveu diversos massacres e, inclusive, deliberadamente introduziu varíola, gripe, tuberculose e sarampo em aldeias indígenas (BRASIL, 2014, p. 207). Nenhum dos perpetradores foi julgado em razão da Lei da Anistia.

Apenas no fim da década de 1970, as organizaçóes não governamentais de apoio aos povos indígenas se multiplicaram, sob a atenção da mídia internacional, e, no início dos anos 80, se organizou um movimento indígena de âmbito nacional.

A mobilização se compôs não só pelos povos indígenas, mas também por juristas progressistas, entidades de apoio aos indígenas (como a Comissão Pró-Índio), antropólogos, comunidades eclesiásticas (como o Conselho Indigenista Missionário), pesquisadores e ativistas dos mais diversos setores sociais que lutavam pela reconstrução da democracia e de uma nova nação. Setores anti-indígenas discutiam a legitimidade dos movimentos, com a determinação, por parte do regime militar, de que o próprio termo "naçóes indígenas" fosse considerado subversivo (FAULHABER-BARBOSA, 2017, p. 397).

É a essa mobilização, articulada de maneira efervescente, diversa e pluralista, que se atribuem as grandes conquistas para a política indigenista nacional trazidas pela Constituição 
Federal de 1988, que reconheceu pela primeira vez os direitos originários dos indígenas, sua permanência e a posse da terra de que foram os primeiros senhores.

Ao questionar a possibilidade de fala do sujeito subalterno, Grada Kilomba (2008, p.26), aponta suas duas fundamentaçóes, de matriz intrinsecamente colonial: a primeira atribui aos grupos subalternizados uma falta de interpretação independente e válida de sua própria opressão, e a segunda atribui a esses grupos subalternizados uma humanidade menor. Ambas tomam os sujeitos colonizados como incapazes de interlocução e, portanto, sem som.

Nessa perspectiva, a Constituição rompeu com o silenciamento imposto pelo Estado aos povos indígenas ao longo dos últimos cinco séculos, permitindo que viessem à tona suas reivindicaçóes, suas pautas, suas vontades e necessidades: com o rasgar do manto do encobrimento que viera, até então, buscando sufocar a todo custo a origem indígena do Brasil, a Constituição Federal de 1988 representou, pela primeira vez, uma possibilidade não só de escuta - mas também de fala.

A próxima seção detalhará, a partir de uma contextualização histórico-teórica, sua dimensáo revolucionária nesse sentido: sua abertura, mesmo que tentativa, às margens da colonialidade e também às suas vozes.

\section{A revolução paradigmática da Constituição Federal de 1988}

A invisibilização histórica dos povos indígenas foi uma opção consciente dos Estados contemporâneos, não só no Brasil como também em toda a América Latina. Nesse sentido, ou os indígenas se adaptavam e se transformavam em cidadãos (em outros termos, conquistavam status de ser humano pleno) ou se mantinham em vida coletiva, à margem da sociedade.

Esse silêncio sempre foi, para Souza Filho (2018, p.85) expressivo, pois o

[...] quanto dizia esse silêncio! Silêncio que era um grito proclamado a todos os povos e todas as gentes que os países latinoamericanos não eram nem queriam ser naçóes indígenas, todos os povos de um mesmo país deveriam ser um só povo, com uma só cultura, um só Deus e só uma cara! (SOUZA FILHO, 2018, p. 85).

Conforme Fachin (1996, p. 147), afinal, o sistema jurídico reflete as relações econômicas e sociais e, com isso, serve para marcar uma marginalização. É dessa forma que uma posição jurídica é somente atribuída a partir do ingresso da pessoa no sistema, da maneira por ele definida: é dessa forma que o sistema jurídico pode ser, antes de tudo, um sistema de exclusão.

A Constituição Federal de 1988, em contraponto e também em sua promessa de revolução permanente, reconheceu pela primeira vez e plenamente a importância das comunidades tradicionais na formaçáo do Estado nacional, renovando assim o olhar jurídico sobre os povos indígenas.

Quanto ao cerne dos direitos fundamentais, a retórica racionalista da modernidade deu lugar ao princípio da dignidade da pessoa humana - a marca da humanidade diante da barbárie, 
na concepção de Barretto (2010, p. 61) -, que passou a consubstanciar fonte legitimadora de todos os demais direitos fundamentais e ainda criou a responsabilidade de se repensar e ressignificar essa mesma dignidade, diante do desafio das ações do poder público voltadas à sua violação (CHAGAS, 2012, p. 5).

Se, até 1988, a política indigenista nacional preservava todas as bases da missão civilizatória europeia - fundada principalmente na tutela exercida pelo Estado e alicerçada tanto na noção de selvageria dos povos originários quanto na certeza de que, com o devido tempo, comunidades indígenas tradicionais simplesmente cessariam de existir - a partir de cinco de outubro, reconheceu-se pela primeira vez o papel dos povos indígenas para a construção do Estado nacional, com a manutenção da proteção sobre seus bens (porque públicos) e um redesenho do instituto da tutela, com a retomada de seu caráter de direito público, expresso pela primeira vez em 1928 e abandonado em 1973.

Em especial, a nova ordem constitucional aceitou a permanência dos povos indígenas, buscando garantir-lhes os meios necessários à manutenção da própria existência. Dessa forma,

[...] ao reconhecer aos povos indígenas direitos coletivos e permanentes, a Constituição abriu um novo horizonte para o país como um todo, criando as bases para o estabelecimento de direito de uma sociedade pluriétnica e multicultural, em que povos continuem a existir como povos que são, independente do grau de contato ou de interação que exerçam com os demais setores da sociedade que os envolve (ARAÚJO, 2006, p. 45).

A presença das lideranças indígenas no processo de redemocratização reforçou a tônica cidadã e popular da Constituição de 1988. Com sua promulgação, as novas diretrizes da política indigenista desconstituíram o ideário de ficta igualdade que buscava, nos termos do Estatuto, "[...] integrá-los, progressiva e harmoniosamente, à comunhão nacional” (BRASIL, 1973, n.p.), e buscaram firmar seu direito à alteridade.

Tal é o direito a ser diferente; a manter práticas e costumes, participar de cultos e falar idiomas distintos dos da sociedade envolvente em uma coexistência pacífica e livre. É um direito, por sua própria natureza, capaz de confrontar a própria universalidade dos direitos (HARVEY, 2015, p. 129).

E, pela primeira vez, os povos indígenas tinham reconhecidas as suas culturas, por mais dissonantes que fossem, de maneira que suas açóes, motivadas por suas crenças e costumes, "[...] não poderiam ser consideradas desprovidas de sentido, nem estigmatizadas como símbolos de atraso" (OLIVEIRA, 2016, p. 220).

De maneira igualmente inédita, foi estabelecido um conjunto doutrinário relativamente articulado do qual o Estado pudesse derivar suas ações e decisões. Como anteriormente a política indigenista era regulada apenas pelo Estatuto, com fundamentos que dependiam de mençóes esparsas encontradas em Constituiçóes anteriores, o campo de trabalho jurídico era, até entáo, extenso em incertezas e vaguezas, usualmente preenchidas pela jurisprudência (OLIVEIRA, 
2016, p. 203). A partir de 1988, contudo, o Estado passou a ter uma política indigenista bastante clara.

Seus pontos centrais, no eixo doutrinário da Constituição Federal, são três: o abandono do integracionismo, a partir do reconhecimento da organizaçáo social, costumes, línguas, crenças e tradiçóes dos povos indígenas (art. 231, caput); a extinção da tutela exercida anteriormente exercida pela Funai; e a garantia aos povos indígenas da posse permanente e o usufruto exclusivo das riquezas do solo, rios e lagos das terras de ocupação tradicional (OLIVEIRA, 2016, p. 203).

De maneira mais detalhada, para Souza Filho (2018, p. 91), a Constituição de 1988 revolucionou a relação entre o Estado e os povos indígenas porque (a) ampliou os direitos indígenas, reconhecendo sua organização social, usos, costumes, religiōes, línguas e crenças; (b) declarou o direito à terra originário; (c) conceituou a terra não só como a necessária à habitação, mas, sim, à produção, à preservação do meio ambiente e à sua reprodução física e cultural; (d) reconheceu a existência de direitos indígenas coletivos, admitindo a existência da organizaçáo social indígena e concedendo a ela o direito de opinar sobre a exploração de recursos naturais e o de postular em juízo; (e) cercou de garantias os procedimentos de aproveitamento dos recursos naturais das terras indígenas; (f) proibiu a remoção de grupos indígenas, salvo exceçôes a serem analisadas pelo Congresso Nacional; e (g) acima de tudo, "[...] chamou os índios de índios e lhes deu o direito de continuarem a sê-lo" (SOUZA FILHO, 2018, p. 91).

A Constituição Federal de 1988, ao não definir explicitamente quais seriam os povos indígenas e quais os critérios para seu reconhecimento, deixou aos próprios povos tradicionais essa identificação. Comprometeu-se expressamente, contudo, com a demarcação e a proteção de suas terras; a manutenção de suas formas tradicionais de vida; e a defesa intransigente de seu direito de permanecer como povos indígenas após cinco séculos sangrentos de integração forçada.

Conforme Herrera Flores (2009, p. 17), entretanto, o direito não surge e nem funciona por si só - e os direitos humanos, em particular, podem converter-se em uma pauta jurídica, ética e social capaz de levar a uma nova racionalidade apenas quando libertados da ideologia de mercado e de sua legitimação formalista e abstrata.

O passo dado pela Constituição Federal de 1988, nesse sentido, foi tentativamente largo: do reconhecimento do caráter originário das terras ao condicionamento da oitiva prévia para exploração de recursos naturais, ela situou os povos indígenas em situação de plena autonomia, reconhecida inclusive em caráter coletivo, em detrimento dos eventuais (e sempre presentes) interesses governamentais desenvolvimentistas.

$\mathrm{Na}$ prática, contudo, persistem os conflitos socioambientais envolvendo terras indígenas, os recursos indispensáveis à sua subsistência e, intrínseca a todas essas questôes, a própria autonomia sociocultural indígena.

É nesse sentido que, para Herrera Flores (2009, p. 21), os direitos humanos também devem se desprender de sua natureza meramente declaratória para que signifiquem a abertura 
de espaços de luta pela dignidade da pessoa humana. Devem compreender, assim, um campo de ação social e política, em que indivíduos possam realizar suas reivindicaçôes e buscar garantir as condições materiais indispensáveis à concretização dos direitos prometidos - porque declarados pelas constituições, declarações ou quaisquer outros instrumentos normativos.

Sob essa perspectiva, a Constituição Federal de 1988 possui uma dimensão emancipadora real, não apenas por - dentro de seu caráter compromissório - ter sido promulgada com a participação de organizaçóes, povos e lideranças indígenas, mas também por ter garantido a essas pessoas, de maneira inédita, o reconhecimento de seus povos como coletivos; a titularidade formal de suas terras; e a legitimidade para defesa em juízo de seus direitos e interesses. A abertura dessa arena política consubstanciou, portanto, um giro político transformador.

Conforme Souza Filho (2013, p. 2150), a Constituição inclusive reconheceu como legítima uma ordem por ela mesma desconhecida, porque calcada nos usos, costumes e nas tradiçôes. Incapaz de abarcar por si essas realidades exógenas, firmou um paradigma de abertura e possibilitou, com isso, releituras de institutos já existentes, especialmente o da propriedade, um dos conceitos basilares do Estado brasileiro.

Como identificado por Araújo Jr. (2018, p. 201), não houve a internalização de cosmovisôes indígenas, bem como previsôes específicas sobre as relações dos povos indígenas com a natureza ou sobre seus mecanismos próprios de deliberação. A partir de uma ecologia de saberes ainda incipiente no continente latino-americano, no entanto, mesmo países que promoveram a constitucionalização de seus saberes e costumes indígenas - a exemplo de Equador (2008) e Bolívia (2009) - não se provaram aptos a, na contemporaneidade, melhor reconhecer e proteger o interesse desses povos (SANTOS, 2019, p. 33).

A mera normatização é, afinal, desprovida de sentido. A revolução promovida pela Constituição Federal de 1988, portanto, foi a de descortinar atores políticos até então invisíveis; a partir do rompimento com a tutela, dotá-los de autonomia para defesa de suas reivindicaçôes; e, sendo seus direitos pontos de partida, apontar um caminho nítido para a construçáo de uma sociedade pluriétnica e intercultural.

Como apontado por Douzinas (2009, p. 379), os direitos humanos são a necessária e também a impossível reivindicação da lei à justiça. A despeito de sua institucionalização homogeneizante, representam ainda um imaginário popular aberto a identidades diversas e a tradiçôes heterogêneas e reprimidas: a luta das pessoas sob a ainda mal definida bandeira da humanidade.

\section{CONSIDERAÇÓES FINAIS}

A partir da chamada emergência indígena, intensificada nas décadas de 70 e 80 e consolidada por meio dos avanços promovidos pela Constituição Federal de 1988 - verdadeira revolução paradigmática nesse sentido - os povos indígenas descortinaram as estruturas do direito brasileiro e, com sua permanência, forçaram o Estado a reconhecer todos os sinais de sua alteridade, histórica e muito viva. 
Eclodem ainda severos conflitos entre os povos indígenas, o Estado e os interesses da sociedade envolvente, que vão desde violentas disputas territoriais, envolvendo tanto o agronegócio latifundiário quanto invasores de toda espécie, grileiros, madeireiros e garimpeiros, a tentativas de grupos religiosos de manterem a todo custo incursóes missionárias, em desrespeito reiterado às garantias constitucionais de liberdade e de auto-organização dos povos originários.

Náo obstante, passados pouco mais de trinta anos da Constituição Federal de 1988, os povos indígenas possuem uma inédita autonomia no cenário nacional. Aptos a se articularem como sujeitos de direito - e não apenas individualmente, como se dá com o direito civil, mas também em coletividade -, tiveram sua existência formalmente reconhecida pelo Estado, assim como a defesa de todas as premissas necessárias à sua proteção.

A conquista prática da concretização de seus direitos fundamentais - e incluem-se aí o direito ao território, à incolumidade, à vida e à alteridade - encontra empecilhos distintos dos obstáculos que, de maneira geral, impedem a todos a existência utópica em uma sociedade livre, justa e solidária. Resvala em pontos sensíveis, com raízes históricas profundas, desde o dificultoso acesso à justiça a concepçóes muito dissonantes das organizaçóes burocráticas e legalistas do Estado nacional.

A Constituição Federal de 1988 deu, entretanto, um largo passo ao romper com essa colonialidade que invisibilizava não só os povos indígenas como, também, suas tradiçôes, crenças, demandas e projetos para o futuro. Ao alçá-los à condição plena de sujeitos livres, não tutelados e sim protegidos pela ordem jurídica, alicerçou as bases para uma discussão política ineditamente mais ampla e democrática.

A partir da perspectiva dos direitos humanos como espaços de luta, destinados à conquista das condiçóes materiais indispensáveis à garantia da dignidade humana, a Constituição Federal representou, portanto, um paradigma transformativo capaz de lançar luz a novos sujeitos e reconhecer abertamente as violências coloniais pretéritas; apto a instaurar uma organização sociopolítica pluralista e propiciar novas formas de diálogo.

Desvinculou-se, dessa forma, de um caráter meramente declaratório, instaurando mudanças concretas e propiciando, principalmente, possibilidades de continuidade das lutas e reivindicaçóes sociais. Apesar de não ter se aberto de maneira mais ampla para os conhecimentos indígenas, por meio de metodologias pós-abissais, rompeu com cinco séculos de silenciamento ao estabelecer as condiçóes mínimas para que seus interlocutores tivessem a liberdade - e a voz - de participar na construção da nação.

Ao Direito, que historicamente se construiu ao empurrar para as margens quaisquer perspectivas que náo a sua própria - e, com isso, a perspectiva daqueles no poder - cabe agora (e ainda) sua reformulação e amplitude, com a quebra dos paradigmas eurocêntricos fundantes e a possibilidade de entrada de novos sujeitos, perspectivas e mesmo objetivos.

Apenas a partir de sua releitura é que se torna possível essa reconstrução. Apenas, portanto, a partir do questionamento sempre presente de seu alinhamento com a ordem pluralista 
e solidária instaurada pela Constituição é que se possibilitam suas mudanças, talvez de maneira mais ampla, talvez mais profunda; decididamente a caminho de uma sociedade mais justa, para superação das opressões e a concretização da dignidade de todas as pessoas humanas.

\section{Referências}

ACÇOLINI, Graziele. Para relembrar... direitos humanos e povos indígenas. In: Mediaçôes. Londrina, v. 15, n.1, p. 92-107, Jan/Jun. 2010. Disponível em: http://www. uel.br/revistas/uel/index.php/mediacoes/article/view/6544. Acesso em: 01 ago. 2020.

ALVARENGA, Rodrigo Canal. Direitos humanos, alteridade e questão indígena: os limites da fundamentação liberal. Revista Interdisciplinar de Direitos Humanos, v. 3, n. 2, p. 147-167, 2015. Disponível em: https://www3.faac.unesp.br/ridh/index.php/ridh/ article/view/290. Acesso em: 01 ago. 2020.

ARAÚJO, Ana Valéria. Povos Indígenas e a Lei dos "Brancos": o direito à diferença. Brasília, MEC/SECAD - LACED/Museu Nacional, 2006.

ARAÚJO JR., Julio José. Direitos territoriais indígenas: uma interpretação intercultural. Rio de Janeiro: Processo, 2018.

ARENDT, Hannah. Sobre a revolução. Tradução de Denise Bottmann. São Paulo: Companhia das Letras, 2011.

BARRETTO, Vicente de Paulo. O fetiche dos direitos humanos e outros temas. Rio de Janeiro: Lumen Juris Editora, 2010.

BRAGATO, Fernanda. Para além do discurso eurocêntrico dos direitos humanos: contribuições da descolonialidade. Revista Novos Estudos Jurídicos, v. 19, n. 1, p. 201 230, 2014. Disponível em: https://siaiap32.univali.br/seer/index.php/nej/article/ view/5548. Acesso em: 01 ago. 2020.

BRASIL. Carta Régia de 13 de maio de 1808. Coleção de Leis do Império do Brasil. Disponível em: https://www2.camara.leg.br/legin/fed/carreg_sn/anterioresa1824/ cartaregia-40169-13-maio-1808-572129-publicacaooriginal-95256-pe.html. Acesso em: 01 ago. 2020.

BRASIL. Código Civil. Lei n 3.071 de $1^{\circ}$ de janeiro de 1916. Disponível em: http:// www.planalto.gov.br/ccivil_03/leis/L3071.html. Acesso em: 01 de agosto de 2020.

BRASIL. Comissão Nacional da Verdade. Relatório. Volume II - Textos temáticos. Violações de direitos humanos dos povos indígenas. Brasília: CNV, 2014. Disponível em: http://cnv.memoriasreveladas.gov.br/images/pdf/relatorio/volume_2_digital.pdf. Acesso em: 01 ago. 2020. 
BRASIL. Decreto 5.484/28. Decreto no 5.484 de 27 de junho de 1928. Disponível em: https://www2.camara.leg.br/legin/fed/decret/1920-1929/decreto-5484-27-junho-1928562434-publicacaooriginal-86456-pl.html. Acesso em: 01 ago. 2020.

CASTRO, Susana de. Condescendência: estratégia pater-colonial de poder. In: HOLLANDA, Heloísa Buarque de. (Org.). Pensamento feminista hoje: perspectivas decoloniais. 1. ed. Rio de Janeiro: Bazar do Tempo, 2020.

CHAGAS, Afonso Maria das. Limites e desafios para os direitos humanos no Brasil: entre o reconhecimento e a concretização. Cadernos IHU ideias, Sáo Leopoldo, ano 10, n. 180, 2012.

CUNHA, Manuela Carneiro da. Índios na Constituição. Novos estud. CEBRAP, São Paulo, v. 37, n. 3, p. 429-443, 2018. Disponível em: https://www.scielo.br/pdf/nec/ v37n3/1980-5403-nec-37-03-429.pdf. Acesso em: 01 ago. 2020.

CUNHA, Manuela Carneiro da. Índios no Brasil: história, direitos e cidadania. São Paulo: Claro Enigma, 2012.

CURIEL, Ochy. Construindo metodologias feministas a partir do feminismo decolonial. In: HOLLANDA, Heloísa Buarque de. (Org.). Pensamento feminista hoje: perspectivas decoloniais. 1. ed. Rio de Janeiro: Bazar do Tempo, 2020.

DOBYNS, H. F. An Appraisal of Techniques with a New Hemispheric Estimate. Current Anthropology, v. 7, n. 4, p. 395-416, 1996. Disponível em: https://www. journals.uchicago.edu/doi/10.1086/200749. Acesso em: 01 ago. 2020.

DORNELLES, Soraia Sales. Trabalho compulsório e escravidão indígena no Brasil imperial: reflexōes a partir da província paulista. Rev. Bras. Hist, vol. 38, n.79, p. 87108, 2018. Disponível em: https://doi.org/10.1590/1806-93472018v38n79-05. Acesso em: 01 ago. 2020.

DOUZINAS, Costas. O fim dos direitos humanos. São Leopoldo: Unisinos, 2009.

DUSSEL, Enrique. Ética da libertação na idade da globalização e da exclusão.

Petrópolis: Vozes, 2000.

FACHIN, Luiz Edson. Da função pública ao espaço privado: aspectos da "privatização" da família no projeto do "Estado Mínimo". In: MARQUES NETO, Agostinho Ramalho (org.). Direito e neoliberalismo. Curitiba: Edibej, 1996.

FAULHABER-BARBOSA, Priscila. Politização indígena e crise da política indigenista no Brasil. Brasiliana - Journal for Brazilian Studies, v. 5, n. 2, p. 391-409, out. 2017. Disponível em: https://tidsskrift.dk/bras/article/view/23122. Acesso em: 01 ago. 2020. 
FEIJÓ, J. A capacidade civil indígena. Revista Brasileira de Direitos Fundamentais \& Justiça, v. 8, n. 28, p. 209-228, 30 set. 2014. Disponível em: http://df.emnuvens.com. br/dfj/article/view/203. Acesso em: 01 ago. 2020.

FERREIRA, Rafael Alem Mello; BITTENCOURT, Fabiana; RÊGO, Alisson Jordão. Direito Indígena e o Paradigma Instituído pela Constituição de 1988: direito à alteridade. Revista de Estudos e Pesquisas sobre as Américas, v. 12, n. 3, 2018. Disponível em: https://periodicos.unb.br/index.php/repam/article/view/20991. Acesso em: 01 ago. 2020.

FLORES, Joaquín Herrera. A reinvenção dos direitos humanos. Florianópolis: Fundação Boiteux, 2009.

HARVEY, David. Espaços de Esperança. 7. ed. São Paulo: Edições Loyola, 2015.

INSTITUTO SOCIOAMBIENTAL - ISA. Quantos são? Povos indigenas no Brasil. 18 nov. 2019. Disponível em: https://pib.socioambiental.org/pt/ Quantos_s\%C3\%A3o\%3F. Acesso em: 31 jul. 2020.

Kilomba, Grada. Plantation memories: Episodes of everyday racism. ( $2^{\text {nd }}$ ed.). Münster: UNRAST Verlag, 2008.

LATOUR, Bruno. Jamais fomos modernos: ensaio de antropologia simétrica. São Paulo: Editora 34, 2013.

MIÑOSO, Yuderkys Espinosa. Fazendo uma genealogia da experiência: o método rumo a uma crítica da colonialidade da razáo feminista a partir da experiência histórica na América Latina. In: HOLLANDA, Heloísa Buarque de. (Org.). Pensamento feminista hoje: perspectivas decoloniais. 1. ed. Rio de Janeiro: Bazar do Tempo, 2020.

OLIVEIRA, João Pacheco de. Sem a tutela, uma nova moldura de nação: O PósConstituição de 1988 e os Povos Indígenas. Brasiliana - Journal for Brazilian Studies, v. 5, n. 1, p. 200-229, nov. 2016. Disponível em: https://tidsskrift.dk/bras/article/ view/23353. Acesso em: 01 ago. 2020.

PERUZZO, Pedro Pulzatto. Direito à consulta prévia aos povos indígenas no Brasil. Revista Direito e Práxis, v. 8, n. 4, p. 2708-2740, dez. 2017. Disponível em: https:// www.e-publicacoes.uerj.br/index.php/revistaceaju/article/view/24631. Acesso em: 01 ago. 2020.

PERUZZO, Pedro Pulzatto. Direitos Humanos, povos indígenas e interculturalidade. Revista Videre, [S.l.], v. 8, n. 15, p. 4-18, jul. 2016. Disponível em: http://ojs.ufgd.edu. br/index.php/videre/article/view/5594. Acesso em: 01 ago. 2020.

QUIJANO, Anibal. Colonialidade do poder, eurocentrismo e América Latina. In: LANDER, E. (Org.). A colonialidade do saber: eurocentrismo e ciências sociais. Perspectivas latino-americanas. Buenos Aires: Colección Sur Sur, CLACSO, 2005. 
RIBEIRO, Darcy. Os indios e a civilização. 7. ed. São Paulo: Global, 2017.

SANTOS, Boaventura de Sousa. O fim do império cognitivo. Belo Horizonte: Autêntica, 2019.

SANTOS, Boaventura de Sousa. Para além do Pensamento Abissal: Das linhas globais a uma ecologia de saberes. Novos estud. - CEBRAP, São Paulo, n. 79, p. 7194, Nov. 2007. Disponível em: https://www.scielo.br/scielo.php?\%20script=sci_ arttext\&pid=S0101-33002007000300004. Acesso em: 01 ago. 2020.

SANTOS, Boaventura de Sousa. Poderá o direito ser emancipatório? Revista Critica de Ciências Sociais, v. 65, p. 3-76, 2003. Disponível em: http://www. boaventuradesousasantos.pt/media/pdfs/podera_o_direito_ser_emancipatorio_ RCCS65.PDF. Acesso em: 04 ago. 2020.

SOUZA FILHO, Carlos F. M. O renascer dos povos indigenas para o direito. $1^{\text {a }}$ ed., (ano 1998), 9ª reimpr. Curitiba: Juruá, 2018.

SOUZA FILHO, Carlos F. M. Comentário ao art. 231. In: CANOTILHO, J. J. Gomes; MENDES, Gilmar F.; SARLET, Ingo W. (Coords.). Comentários à Constituição do Brasil. São Paulo: Saraiva, 2013.

SUCHANEK, Márcia Gomes O. Povos indígenas no Brasil: de escravos à tutelados. Uma difícil reconquista da liberdade. Confluências, v.12, n.1, p.240-274, 2012. Disponível em: https://periodicos.uff.br/confluencias/article/view/34240. Acesso em: 01 ago. 2020.

VALENTE, Rubens. Os fuzis e as flechas. São Paulo: Companhia das Letras, 2017. 